\title{
Sistematização de requisitos do usuário com o uso da Casa da Qualidade do QFD na etapa de concepção de unidades habitacionais de interesse social no âmbito do Programa Minha Casa, Minha Vida
}

\author{
Systematization of user requirements using QDF's House \\ of Quality at the conceptual stages of low-income housing \\ projects for the Programa Minha Casa, Minha Vida
}

\section{Danilton Luis Lima Jesus de Aragão Ercília Hitomi Hirota}

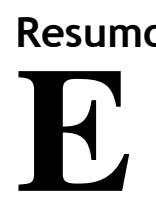

Resumo

ste artigo propõe a estruturação e a organização dos requisitos do usuário como dados de entrada no processo de projeto de habitações de interesse social (HIS), de forma a propiciar o desenvolvimento de um produto com atributos que melhor atendam às necessidades dos usuários. Para o desenvolvimento da pesquisa adotou-se o estudo de caso como estratégia. Numa primeira etapa foi realizado um estudo visando compreender o escopo de requisitos de usuários de empreendimentos habitacionais de interesse social (EHIS) e levantar as restrições legais, normativas e técnicas que influenciariam no processo de projeto. Este estudo teve como pontos de partida uma revisão bibliográfica, com o objetivo de compreender os mecanismos para a sistematização de requisitos, e os resultados de uma avaliação de satisfação dos clientes realizada em um EHIS destinado a famílias com renda de até três salários mínimos. Em seguida, realizou-se um estudo de caso com intervenção, que consistiu na organização e disponibilização de informações que visavam à consideração dos requisitos do usuário no projeto de uma HIS, desenvolvido por uma equipe multidisciplinar, para o qual foi estabelecido um custo-meta. $\mathrm{O}$ artigo contribui com uma estruturação e uma organização dos requisitos do usuário e respectivos procedimentos, apoiadas no uso de Desdobramento da Função Qualidade (QFD), para o desenvolvimento de unidades de HIS no âmbito do Programa Minha Casa, Minha Vida (PMCMV).

Palavras-chaves: Análise de requisitos. QFD. Habitação de Interesse Social.
Danilton Luis Lima Jesus de Aragão Centro Universitário Filadélfia Londrina - PR - Brasil

Ercília Hitomi Hirota Universidade Estadual de Londrina Londrina - PR - Brasil

Recebido em 15/01/15 Aceito em 02/05/16

\begin{abstract}
This paper proposes the structuring and organization of users' requirements as inputs at the early stages of the design process of low-income housing projects, within the "Minha Casa, Minha Vida" Program. This objective of this proposition is to develop a product with more a more value-added product. The research strategy adopted was the case study. After a literature review aimed at understanding the mechanisms used to systematize requirements, a case study was conducted in a low-income housing project developed for families earning up to three minimum wages. That exploratory study sought to capture users' requirements based on a users' satisfaction assessment applied in the project. Based on the results achieved, a case study was undertaken, in which the researcher collaborated with the design team, focusing on the organization and provision of information for the consideration of users' requirements, since a target cost had been given to the design team. Finally, this paper presents a structure and organization of users' requirements, as well the respective procedures, based on the use of QFD, for the development of low-income housing units under the "Minha Casa, Minha Vida" Program.

Keywords: Requirements analysis. QFD. Social housing.
\end{abstract}




\section{Introdução}

Embora a carência por habitações seja um tema relevante e continuamente discutido, observa-se ainda um forte questionamento quanto à qualidade das habitações que vêm sendo produzidas. Miron (2008) aponta que, embora estejam sendo desenvolvidos diversos estudos sobre o tema habitação, muitas lacunas acerca do atendimento das necessidades dos usuários permanecem (QUEIROZ; TRAMONTANO, 2009; DIKMEN; TALAT BIRGONUL; KIZIKTAS, 2005; YANG et al., 2003), o que reforça a necessidade de buscar uma melhor definição de soluções de projeto, visando ao aumento do valor percebido pelo usuário.

O empenho na produção do maior número de casas com a maior agilidade possível ocorre em detrimento ao valor agregado à unidade habitacional, o que tem refletido diretamente na redução qualitativa das unidades e, consequentemente, na insatisfação de seus usuários (PALERMO et al., 2007).

Logsdon (2012) destaca ainda a falta de atenção dos programas governamentais voltados à habitação de interesse social, sobretudo quanto à qualidade dos projetos que há décadas replicam as mesmas soluções e características projetuais (Figura 1).

Os empreendimentos habitacionais de interesse social (EHIS) acabam oferecendo habitações mínimas e com programa restrito, o que resulta em modificações realizadas pela grande maioria dos moradores tão logo ocupem as habitações. Essas modificações geram, via de regra, prejuízos à qualidade das edificações (BRANDÃO, 2011).

Segundo Oliveira (2006), o grupamento familiar desenvolve uma transposição de necessidades ao longo do que se chama estágios de ciclo de vida. Esses estágios apresentam configurações de ocupantes cujas necessidades variam e se diferenciam demais ao longo do tempo, afetando o funcionamento da moradia. Diante do desconhecimento quanto à evolução das necessidades de cada família durante o uso da habitação, os projetos precisam ser dotados de flexibilidade, para que as famílias possam buscar a adequação às necessidades futuras.

No entanto, na construção de HIS, observa-se uma perpetuação de modelos consagrados, porém com características construtivas e tipológicas conservadoras, marcadas pela inclemente e monótona repetição (KANASHIRO; GUADANHIM; DEMORI, 2012). É comum observar situações em que há um grande esforço por parte dos usuários no sentido de se adequarem aos espaços edificados, quando seria razoável que ocorresse o contrário (QUEIROZ; TRAMONTANO, 2009).

Logo, o tema abordado neste artigo é motivado pela possibilidade de contribuir para mudanças nas práticas atuais de desenvolvimento de HIS por meio da utilização de estratégias mais modernas e proativas que possam proporcionar melhor equilíbrio entre o atendimento dos requisitos do usuário e os recursos financeiros disponíveis.

Nesse sentido, a questão principal a ser respondida neste artigo é: como organizar de forma sistemática os requisitos do usuário para a melhor consideração da demanda durante a etapa de concepção de unidades habitacionais de interesse social no âmbito do Programa Minha Casa, Minha Vida (PMCMV)?

\section{Figura 1 - Padronização histórica das HIS}

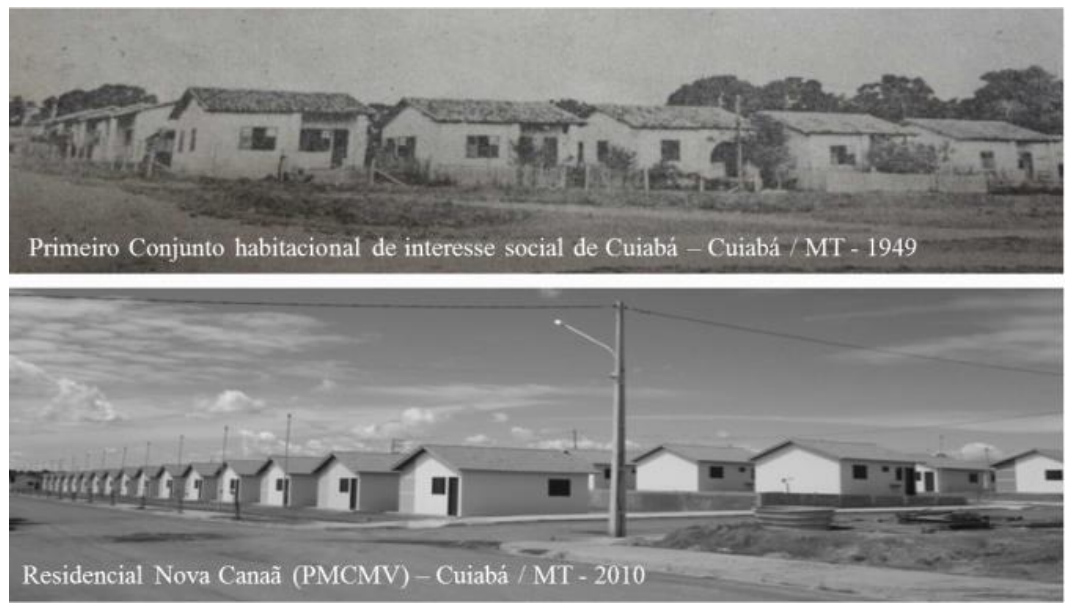

Fonte: modificado de Logsdon (2012). 
Essa questão está fundamentada na proposição de que a Casa da Qualidade do QFD é uma estratégia favorável à sistematização dos requisitos do usuário para o desenvolvimento de projetos de HIS no âmbito do PMCMV, pois grande parcela dos projetos de HIS são desenvolvidos sem que haja uma clara avaliação e consideração dos requisitos do usuário.

Portanto, o objetivo deste artigo é propor procedimentos para o uso do QFD para a estruturação e organização dos requisitos do usuário, desenvolvidos em um caso real, durante a etapa de concepção do processo de projeto de habitações destinadas a famílias com renda de até três salários mínimos, no âmbito do PMCMV, por uma equipe multidisciplinar de projetistas. Tais procedimentos fundamentam a utilização de estratégias que visam ao desenvolvimento de um produto com maior valor agregado, mesmo diante de limitações de custos.

\section{Fundamentação teórica}

Thieme (2007) define processo de desenvolvimento de produto (PDP) como um conjunto de atividades que envolvem desde a coleta de informações junto aos clientes até o lançamento dos produtos no mercado, ou seja, sistematiza a transformação das necessidades e expectativas dos clientes em especificações técnicas do produto. Essa concepção implica maior integração entre o projeto e a produção, tendo como foco os requisitos dos clientes (COOPER, 1999).

Segundo Salgado et al. (2006), o PDP pode ser considerado um processo de difícil visualização devido a sua natureza dinâmica, grande interação

Figura 2 - Tripé e zona de sobrevivência

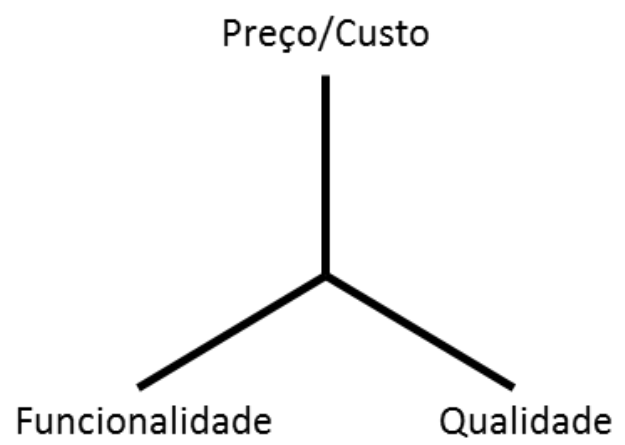

Fonte: modificado de Cooper e Slagmulder (1997). com as demais atividades da empresa e grande volume de informações manipuladas.

A eficácia do PDP decorre do equilíbrio entre três dimensões, custo/preço, qualidade e funcionalidade, o que Cooper e Slagmulder (1997) denominaram como tripé de sobrevivência de uma empresa no mercado. Essas dimensões são interdependentes, implicando a necessidade de balanceá-las de modo que o produto desenvolvido atenda às expectativas dos clientes. Além disso, essas dimensões definem uma zona de sobrevivência, apresentada na Figura 2, definida por limites mínimos e máximos de preço/custo, qualidade e funcionalidade de um produto, sob a perspectiva do cliente ou usuário. Segundo Cooper e Slagmulder (1997), um produto só será competitivo para a empresa se ele estiver dentro de sua zona de sobrevivência.

Cooper e Slagmulder (1997) apresentam o custeiometa como uma estratégia adotada para o PDP, que busca, essencialmente, agregar o máximo valor ao produto, atendendo às restrições de custo e às expectativas de lucro da empresa. Contudo, esses mesmos autores ressaltam que a percepção de valor pode variar dependendo da perspectiva de quem o avalia. Sendo assim, a definição do interlocutor é determinante para se definir o conceito de valor. Para quem produz, valor pode representar uma proporção entre a funcionalidade $\mathrm{e}$ o custo. No entanto, sob o ponto de vista do usuário, tal funcionalidade atribuída ao produto só reflete valor se for interpretada como um benefício e não representar aumento no preço além do que o cliente se dispõe a pagar. Assim, valor, na perspectiva do cliente final, é a relação entre preço e benefício (COOPER; SLAGMULDER, 1997).

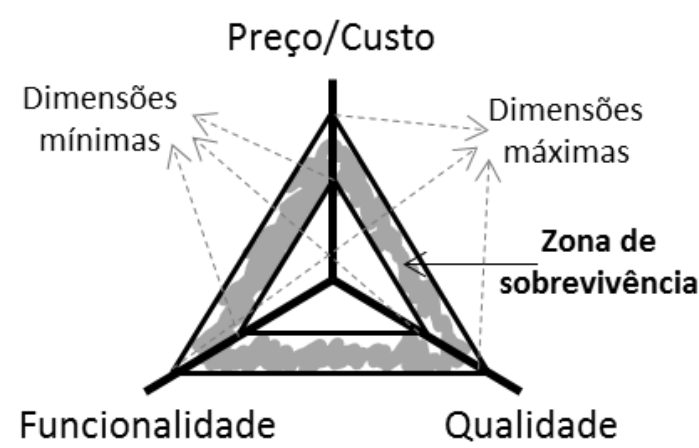


Para Salvatierra-Garrido, Pasquire e Miron (2012), o valor deve ser estabelecido nas etapas iniciais de projeto, nas quais se encontram as maiores possibilidades de equilíbrio entre o atendimento dos requisitos do usuário e os recursos financeiros disponíveis. É importante esclarecer que no âmbito do PMCMV a concepção do produto habitação passa necessariamente por limitações orçamentárias. Por outro lado, os recursos financeiros são previamente definidos: para o desenvolvimento de unidades HIS, o preço do produto é definido pelo próprio programa. Para Londrina, município onde se desenvolve o presente trabalho, o recurso de financiamento corresponde a $\mathrm{R} \$$ 64.000,00 (referente ao ano de 2013). Portanto, torna-se fundamental compreender as prioridades requeridas e, a partir disso, identificar os atributos do produto que possam representar valor para o cliente diante das restrições orçamentárias. Em outras palavras, compreender os requisitos do usuário garante maior eficiência no gerenciamento de trade-offs diante das reais possibilidades financeiras.

Para compreender a importância da sistematização dos requisitos do usuário para a agregação de valor ao produto edificado, é fundamental definir o conceito de valor, pois este termo extrapola a dimensão meramente econômica.

Salvatierra-Garrido, Pasquire e Miron (2012) delinearam a evolução do conceito de valor segundo o ponto de vista dos diversos pesquisadores que têm contribuído para o desenvolvimento do conhecimento na área da construção enxuta, a partir da análise de 52 artigos publicados ao longo dos 19 anos de existência do International Group for Lean Construction (IGLC), referência no assunto. Esses autores concluíram que já há consenso em torno de alguns pontos. Um deles é o de que valor de um produto é definido pelo cliente e é gerado pelo atendimento das necessidades e requisitos do cliente. No entanto, esses mesmos autores expõem a natureza complexa do valor, ressaltada pela subjetividade, pela dinamicidade e pela forte influência que o contexto exerce sobre a percepção do valor por parte do cliente.

Miron (2008), por sua vez, estabelece o conceito de valor para o cliente final como a ponderação de trade-offs entre os benefícios percebidos e os sacrifícios exigidos.

Portanto, valor não resulta da eficiência do processo de produção, mas da percepção de quem necessita do produto. Dessa forma, é importante compreender quais as prioridades requisitadas pelo cliente e, a partir disso, identificar os requisitos a serem incorporados ao produto que possam atribuir valor a ele.

Kowaltowski e Granja (2011) apresentam ainda um instrumento voltado à identificação, captura e hierarquização dos requisitos do usuário. Isto por meio da aplicação de cartas ilustradas, com as quais o usuário pode classificar, segundo a relevância, cada item apresentado. Assim, os dados coletados permitem um tratamento estatístico das informações, que resulta na hierarquização dos requisitos do usuário, o que os autores descrevem como índice geral de importância (IGI). Essa lógica de agregação de valor evidencia a importância das etapas iniciais de concepção do produto e a necessidade de mecanismos que possam apoiar a captura e a análise dos requisitos do usuário, bem como garantir a consideração destes mediante um gerenciamento proativo e coeso dos recursos financeiros disponíveis. O gerenciamento de requisitos é um dos pilares para a entrega de valor agregado ao produto.

Koskela (2000) estabelece princípios para geração de valor, entre os quais se destaca a necessidade de se assegurar que todos os requisitos do cliente tenham sido capturados para alimentar o desenvolvimento do projeto do produto. Mesmo considerando que algumas necessidades ou requisitos não possam ser explicitados diretamente pelo cliente, Koskela (2000) enfatiza que esse é o primeiro e fundamental passo para a agregação de valor ao produto.

A partir da identificação dos requisitos, é preciso assegurar também que os requisitos relevantes para o cliente sejam considerados e transformados em soluções de projeto e planos para produção, e, por fim, incorporados ao produto (KOSKELA, 2000).

Conforme observado por Kamara, Anumba e Evbuomwan (1999), os requisitos dos clientes precisam ser processados em função da complexidade de cada cliente, da natureza dos requisitos do empreendimento e da necessidade de trabalho colaborativo entre os profissionais da construção. Segundo Austin et al. (2007), o trabalho colaborativo tem como princípios a identificação de tarefas, a distribuição de responsabilidades e o foco nas soluções que agreguem valor. Kvan $\left(2000^{1}\right.$ apud OZORIO, 2012) sugere que projeto colaborativo deveria ser denominado "projeto comprometido", para garantir o entendimento do que realmente deve acontecer: o comprometimento de cada um para atingir o objetivo comum. Kamara, Anumba e Evbuomwan (1999) argumentam ainda que é essencial processar as necessidades e as

${ }^{1} \mathrm{KVAN}, \mathrm{T}$. Collaborative Design: what is it? Automation in Construction, Amsterdam, v. 9, n. 4, p. 409-415, Jul. 2000. 
expectativas do cliente em um formato que aumente a compreensão da equipe de desenvolvimento do produto.

Baldauf, Formoso e Miron (2013) propõem a modelagem de requisitos de clientes de empreendimentos HIS com o uso de Building Information Modeling (BIM) ${ }^{2}$. Estes autores citam que o gerenciamento de requisitos do cliente visa melhorar a geração de valor em empreendimento de construção por meio da sistematização de informações.

São muitas as metodologias que propõem a sistematização de requisitos, sobretudo desenvolvidas no âmbito da indústria de manufatura. Autores como Becker et al. (2008) e Lima, Formoso e Echeveste (2011) recomendam o QFD como método para o processamento de requisitos do cliente em produtos da construção civil.

\section{QFD como método para o processamento de requisitos}

O desdobramento da função qualidade, como é mais conhecido o QFD no Brasil, foi idealizado no Japão na década de 1960 (AKAO, 1997), projetado originalmente para captar a voz do cliente e traduzi-la em parâmetros de projeto (PRASAD, 1998). Por sua vez, o QFD é definido por Akao (1997) como uma metodologia que converte as demandas dos usuários em características de qualidade e funcionalidade adicionais ao produto. Assim, o fornecedor agrega valor ao produto conforme $\mathrm{o}$ atendimento das necessidades $\mathrm{e}$ desejos requeridos pelos usuários (KOSKELA, 2000), ou seja, em definição genérica o QFD traduz as necessidades do cliente em requisitos de projeto.
O modelo conceitual do QFD é formado por um conjunto de matrizes. No entanto, muitas vezes por questão de praticidade é implementada apenas a primeira matriz, conhecida como Casa da Qualidade, a qual, segundo Thia et al. (2005), já pode resultar em benefícios para o desenvolvimento do produto. A Casa da Qualidade permite estabelecer relações entre as funções técnicas de um produto e as necessidades dos usuários (HAUSER; CLAUSING, 1988). A estrutura básica da Casa da Qualidade está representada na Figura 3.

Segundo Han et al. (2001), a aplicação da Casa da Qualidade se divide em seis etapas básicas:

(a) identificação e hierarquização dos requisitos do cliente;

(b) especificação dos requisitos mensuráveis de projeto com base nas solicitações do cliente captadas na etapa anterior;

(c) definição das relações entre os requisitos do cliente e os requisitos de projeto nos níveis forte, moderado e fraco;

(d) análise competitiva, pela qual se realiza o benchmarking competitivo, com o objetivo de identificar o nível de satisfação do cliente ou usuários de produtos similares ao em desenvolvimento;

(e) definição das correlações positivas ou negativas entre os atributos de projeto em níveis forte, médio ou neutro, com objetivo de auxiliar a equipe técnica na tomada de decisões sobre possíveis trade-offs; $\mathrm{e}$

(f) especificações-meta de projeto e dificuldade técnica, sendo que esta última consiste na definição de algarismos de 1 a 5, usados para indicar o nível de dificuldade técnica envolvida para cumprir determinado requisito de projeto.

\section{Figura 3 - Estrutura básica da Casa da Qualidade}

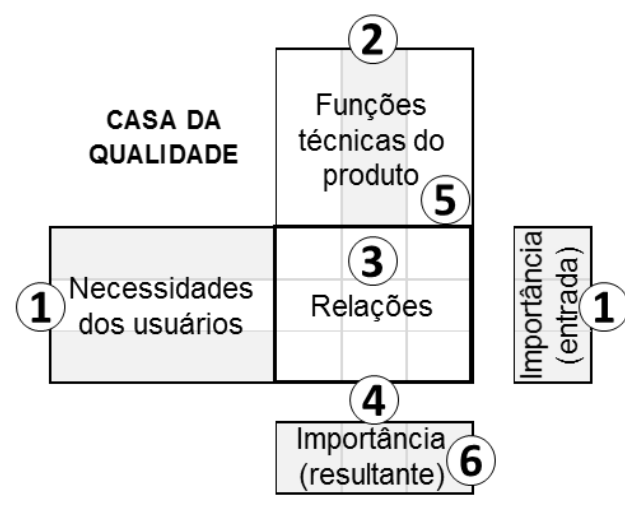

${ }^{2}$ Segundo a ABNT (2010), Building Information Modeling traduz-se por Modelagem de Informações da Construção. 
De mneira geral, após a identificação dos requisitos do cliente e a definição dos requisitos de projeto com base nas solicitações do cliente, é aplicada a matriz de relações, a partir da qual são identificadas as características técnicas que afetam tais solicitações do cliente e, também, a relevância das relações estabelecidas entre os requisitos do usuário e os requisitos do projeto. Para Kamara, Anumba e Evbuomwan (1999), essa relação deve ser definida em três níveis, forte, moderado e fraco, representados respectivamente pelos algarismos 9, 3 e 1 e/ou pelos símbolos $\odot, \mathrm{O}$ e $\Delta$ (Figura 4).

No entanto, o QFD é, a princípio, direcionado para produtos simples e pode se mostrar limitado para o desenvolvimento de produtos complexos como os da construção civil (SOMMERVILLE; CRAIG, 2002).

A aplicação do QFD na indústria da construção ainda é incipiente, com poucos exemplos de aplicação relatados na literatura. Sampaio et al. (2011) incluíram a Casa da Qualidade no modelo proposto para retroalimentação das informações sobre satisfação de clientes para o processo de projeto. Embora não tenham apontado dificuldades específicas, esses autores não puderam aplicar o modelo em casos reais de processo de projeto. Contudo, as eventuais dificuldades decorrentes da complexidade do produto evidenciam não a impossibilidade de sua aplicação na indústria da construção, mas a necessidade de adaptações do método a fim de propiciar novas alternativas de uso, mais adequadas ao contexto (DIKMEN; TALAT BIRGONUL; KIZILTAS, 2005), sobretudo porque a indústria da construção tem sido criticada pela falha no atendimento aos requisitos do usuário, especialmente em relação aos EHIS. Um dos problemas recorrentes refere-se ao design precoce das edificações, no qual os projetistas dispõem de poucas informações sobre os requisitos do usuário, e assim desenvolvem programas de necessidades a partir de suas próprias experiências, fazendo com que esses programas tenham o viés do profissional que o desenvolveu (BARRETT; HUDSON; STANLEY, 1999).

Em última instância, a falta de valorização das etapas de concepção dos empreendimentos da construção civil pode significar a perda de foco sobre o cliente final, usuário das edificações, resultando no que Queiroz e Tramontano (2009) definem como um cenário de uniformidade de soluções no qual o usuário precisa se adaptar ao produto ao invés de o produto atender às expectativas do usuário.

Dikmen, Talat Birgonul e Kiziltas (2005) também ressaltam que na indústria da construção geralmente as necessidades e os requisitos do usuário não são tratados de forma adequada e sistemática. Além disso, Yang et al. (2003) observam que os projetistas muitas vezes não têm as informações necessárias para o processo de tomada de decisão nas fases iniciais de projeto, que tende a ser mal estruturado e ocorre de forma assistemática. Segundo eles, o QFD pode auxiliar nisso porque contribui para o desenvolvimento de um método estruturado e sistemático no processo de design, facilitando a implementação de decisões.

É importante destacar ainda que a eficiência do processo de sistematização de requisitos passa necessariamente pela integração e pela colaboração efetiva entre as diferentes áreas e profissionais ligados ao desenvolvimento do produto (CUNHA, 2008). Adicionalmente, Robin, Rose e Girard (2007) citam que a eficiência do trabalho colaborativo está diretamente ligada à facilitação e à pertinência de intercâmbio de conhecimento entre os agentes do processo.

Figura 4 - Níveis das relações definidas na Casa da Qualidade

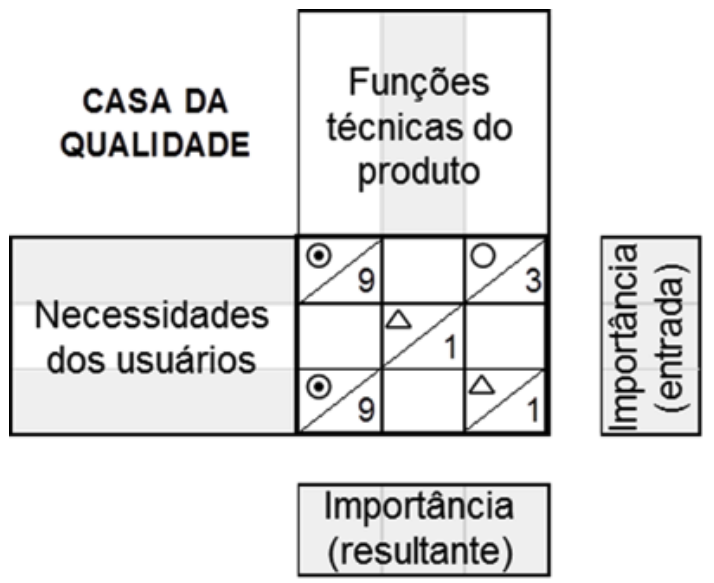

276 Aragão, D. L. L. J. de; Hirota, E. H. 


\section{Método de pesquisa}

O estudo apresentado neste artigo faz parte de um projeto desenvolvido no âmbito de uma rede de pesquisas, denominada Zero-Energy Mass Custom Home Brasil (ZEMCH Brasil), que tem como objetivo promover a colaboração entre academia e indústria para buscar soluções mais sustentáveis e customizadas em massa para a produção de habitações sustentáveis. A estratégia adotada nessa rede de pesquisas consiste na valorização da etapa de concepção do produto habitacional, levando em conta os requisitos do usuário, requisitos de sustentabilidade, notadamente a eficiência energética, com ênfase na agregação de valor por meio de uma gestão adequada do processo de desenvolvimento do produto.

Os autores deste artigo tiveram como função, na equipe de desenvolvimento do projeto, a estruturação das informações relativas às necessidades do usuário, diante de restrições orçamentárias, para favorecer a agregação de valor ao produto na etapa inicial do processo de projeto de unidades habitacionais de interesse social no âmbito do PMCMV, produzido com o uso de painéis pré-fabricados em woodframe.

A equipe de colaboradores envolvidos neste estudo era composta de profissionais das áreas de arquitetura, engenharia, assistência social, construtores, mestrandos e graduandos, conforme a relação a seguir:

(a) engenheira civil, doutora em Engenharia Civil com mais de trinta anos de experiência acadêmica, que tem atuado em pesquisas acadêmicas com ênfase em Gestão da Construção;

(b) arquiteto e urbanista, doutor em Arquitetura e Urbanismo com vinte e um anos de experiência acadêmica e experiência profissional na área de Planejamento e Projetos da Edificação;

(c) engenheira civil, doutora em Engenharia Civil com dezesseis anos de experiência acadêmica e experiência profissional nas áreas de Gestão da Produção, Padronização e Prototipagem;

(d) arquiteto e urbanista, doutor em Arquitetura e Urbanismo com dezesseis anos de experiência acadêmica e experiência profissional nas áreas de Habitação de Interesse Social, Projeto Participativo e Avaliação Pós-Ocupação;

(e) engenheiro civil com mais de vinte e cinco anos de experiência profissional, que exerce a função de diretor técnico de empresa privada do setor construtivo;

(f) engenheiro civil com vinte anos de experiência profissional, que ocupa cargo público na Companhia Habitacional do município de Londrina, atua há doze anos na área de projeto e construção de EHIS, e já gerenciou a construção de mais de quatro mil unidades habitacionais;

(g) assistente social, chefe do Departamento Social da companhia habitacional do município de Londrina;

(h) arquiteto e urbanista, mestrando de Engenharia Civil com cinco anos de experiência profissional na coordenação de projetos com ênfase em Planejamento e Projetos da Edificação;

(i) arquiteto e urbanista, mestrando de Engenharia Civil com experiência profissional de dois anos como profissional liberal na área de Arquitetura e Urbanismo;

(j) arquiteta e urbanista, mestranda de Arquitetura e Urbanismo com experiência profissional de quatorze anos como profissional liberal na área de Arquitetura e Urbanismo;

(k) arquiteta e urbanista, mestranda de Arquitetura e Urbanismo; e

(1) arquiteta e urbanista, mestranda de Arquitetura e Urbanismo com experiência acadêmica e como profissional liberal na área de Arquitetura e Urbanismo.

\section{Delineamento da pesquisa}

A Figura 5 indica as interfaces entre a pesquisa relatada neste artigo e o processo de pesquisa desenvolvido pela equipe da Rede ZEMCH Brasil (na cor cinza).

Para fundamentar as ações desenvolvidas ao longo deste trabalho, a primeira etapa consistiu em uma revisão bibliográfica sobre a geração de valor agregado ao produto e a aplicação estratégica do método QFD como meio para sistematização de requisitos.

Posteriormente à revisão da literatura, desenvolveu-se uma pesquisa focada em capturar e compreender o escopo de requisitos do usuário de um EHIS e levantar as restrições legais, normativas e técnicas que influenciariam no processo de projeto e, consequentemente, o atendimento dos requisitos do usuário. 
Figura 5 - Delineamento da pesquisa

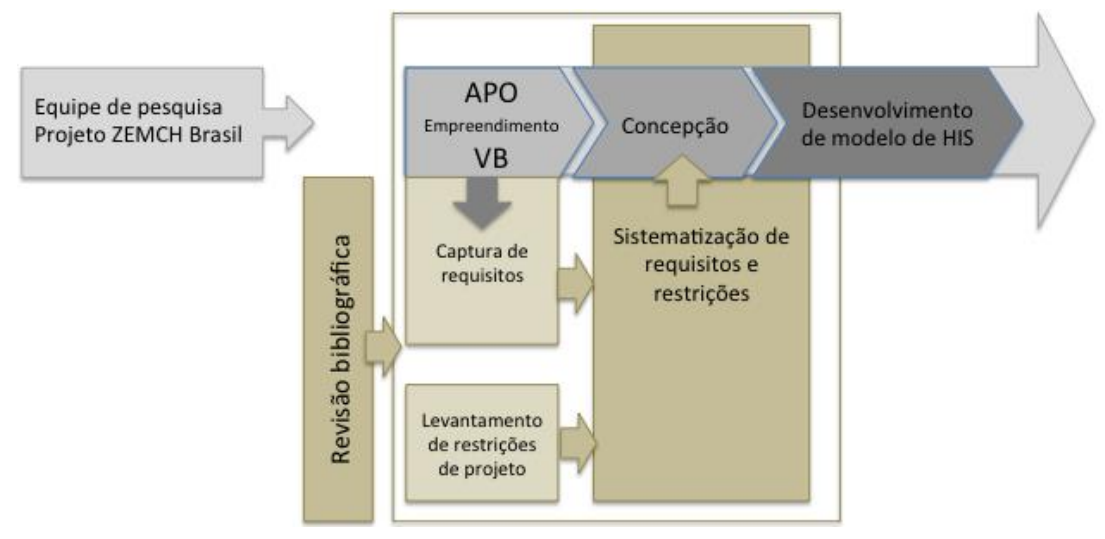

A partir do resultado obtido, no qual ficou evidente a amplitude do escopo e a grande complexidade dos requisitos do usuário, desenvolveu-se a terceira etapa do estudo, em tempo real à etapa de concepção do processo de projeto de habitações destinadas a famílias com renda de até três salários mínimos por uma equipe de projetistas denominada neste artigo como equipe de desenvolvimento do produto. Nesta etapa, buscouse disponibilizar para a equipe de desenvolvimento do produto as informações relativas às necessidades do usuário e restrições projetuais, de forma a propiciar a tomada de decisão no processo de projeto e, consequentemente, maior agregação de valor ao produto.

\section{Captura de requisitos e levantamento de restrições}

Esta etapa foi desenvolvida por equipe composta dos profissionais elencados nos tópicos a, d, g, i, j, k e 1 , conforme a descrição na seção anterior, e envolveu:
(a) captura dos requisitos do usuário; e
(b) levantamento das restrições de projeto.

A captura dos requisitos do usuário foi desenvolvida em um EHIS localizado na cidade de Londrina, PR, entregue entre os anos de 2011 e 2012, considerado uma das maiores ações do PMCMV. Esse empreendimento abriga uma população de aproximadamente 10 mil pessoas em 2.712 moradias, sendo 1.440 apartamentos e 1.272 unidades unifamiliares.

Foram investigadas neste estudo apenas as unidades unifamiliares, das quais foi selecionada uma amostra de 93 unidades, distribuídas de forma homogênea no conjunto, considerando a orientação solar delas.

Foram entrevistados os proprietários ou os responsáveis pelas unidades, dos quais $84 \%$ eram mulheres com idade entre 25 e 44 anos. Destas, $85,6 \%$ não possuíam vínculo empregatício formalizado e tinham como principal fonte de renda o trabalho temporário ou como empregada doméstica. Em 71,2\% das habitações residiam crianças de até 10 anos de idade, em 29,6\% crianças entre 11 e 14 anos, e em $21,6 \%$ adolescentes entre 15 e 17 anos.

Para essa coleta de dados aplicou-se o instrumento de avaliação pós-ocupação (APO) desenvolvido por Kowaltowski e Granja (2011) para edifícios multifamiliares e adaptado pela equipe envolvida neste estudo para usuários de unidades unifamiliares. Detalhes acerca dos procedimentos adotados nesta coleta de dados encontram-se em Conceição, Imai e Urbano (2015).

Para o levantamento das restrições, foi feita consulta a legislações, normas e outros documentos de caráter técnico, a fim de identificar possíveis incentivos ou embargos ao atendimento dos requisitos do usuário. Os documentos consultados foram: Código de Obras Municipal (LONDRINA..., 2011); Norma de Desempenho (ABNT, 2013a, 2013b, 2013c, 2013d, 2013e, 2013f); Regulamento Técnico da Qualidade (Decreto federal $n^{\circ}$ 6.275/2007 (INSTITUTO..., 2007)); Ministério das Cidades (2004); Plano Diretor Participativo Municipal (1998); Estatuto do Idoso (BRASIL, 2003); e Cartilha de Disposições Técnicas do PMCMV (CAIXA, 2012).

Em vista do grande número de informações captadas (173 itens), houve necessidade de dispor as informações de forma que facilitasse a leitura e a consulta mais rápidas, de forma a permitir compreensão por parte da equipe de desenvolvimento do produto. Para tanto, foram ocultadas, a pedido da equipe de desenvolvimento do produto, as informações referentes ao meio 
urbano, loteamento, localização do empreendimento, infraestrutura, e foram eliminadas duplicidades de informações coletadas em fontes distintas. Além disso, nos casos de restrições diferentes sobre a mesma temática, adotou-se aquela com maior grau de restrição, como o caso no qual o PMCMV estabelece pédireito mínimo de 2,30 m nos banheiros e 2,50 m nos demais cômodos, enquanto o Código de Obras local exige pé-direito mínimo de $2,30 \mathrm{~m}$ nos banheiros e 2,60 m nos demais cômodos, prevalecendo, nesse caso, as exigências da última norma.

Outro meio pelo qual se buscou a compactação da lista de restrições foi o agrupamento de informações complementares de mesma temática. Um exemplo são as informações presentes no Código de Obras que informam:

(a) a cozinha deve ter área mínima de 4,50 m²; e

(b) a cozinha deve ter espaço para um círculo inscrito de 1,50 m de diâmetro.

Tais informações agrupadas tornaram-se uma única restrição referente ao dimensionamento da cozinha: cozinha com área mínima de $4,50 \mathrm{~m}^{2} \mathrm{e}$ com espaço para um círculo inscrito de $1,50 \mathrm{~m}$ de diâmetro.

\section{Sistematização dos requisitos e restrições}

Esta etapa compreendeu a realização de fóruns de discussões com a participação dos profissionais elencados nos tópicos a, b, c, d, h, i, j, k e 1, conforme a descrição anterior, e envolveu:

(a) análise e transformação dos requisitos do usuário em requisitos de projeto; e

(b) hierarquização dos requisitos de projeto e análise de restrições.
Com objetivo de propiciar o atendimento das necessidades do usuário durante o processo de projeto, baseado no trabalho colaborativo e na experiência profissional da equipe de desenvolvimento do produto, durante os fóruns de discussões, os requisitos do usuário foram transformados em requisitos de projeto mensuráveis. A equipe envolvida nesse processo analisou os itens requeridos pelo usuário, transformando cada um deles em uma ou mais características projetuais, as quais foram referidas como requisitos de projeto. Como exemplo desse processo pode-se citar o item privacidade, requisito do usuário, o qual foi transformado nos seguintes requisitos de projeto: fechamento da unidade habitacional (UH) com muro; bloqueio visual nas aberturas laterais entre unidades vizinhas; e UH independente, não geminada. Um dos cuidados tomados nesse processamento de informação foi a definição de itens mensuráveis, ou seja, requisitos de projetos que pudessem ser medidos, de forma a haver a possibilidade de identificar o grau de concretização de cada requisito do produto. Como tática para essa etapa de processamento de requisitos, adotou-se a estrutura exposta na Figura 6.

Nesta fase foram aplicados os procedimentos para o processamento dos requisitos e, posteriormente, a transformação destes em especificações-meta para o produto em desenvolvimento. Este trabalho dividiu-se em:
(a) síntese dos requisitos do usuário relacionados ao desenvolvimento da unidade habitacional;
(b) valoração dos requisitos do usuário;
(c) elaboração do conjunto de requisitos de projeto; e

(d) definição das especificações-meta do produto.

Figura 6 - Estágios para a conversão dos requisitos do usuário

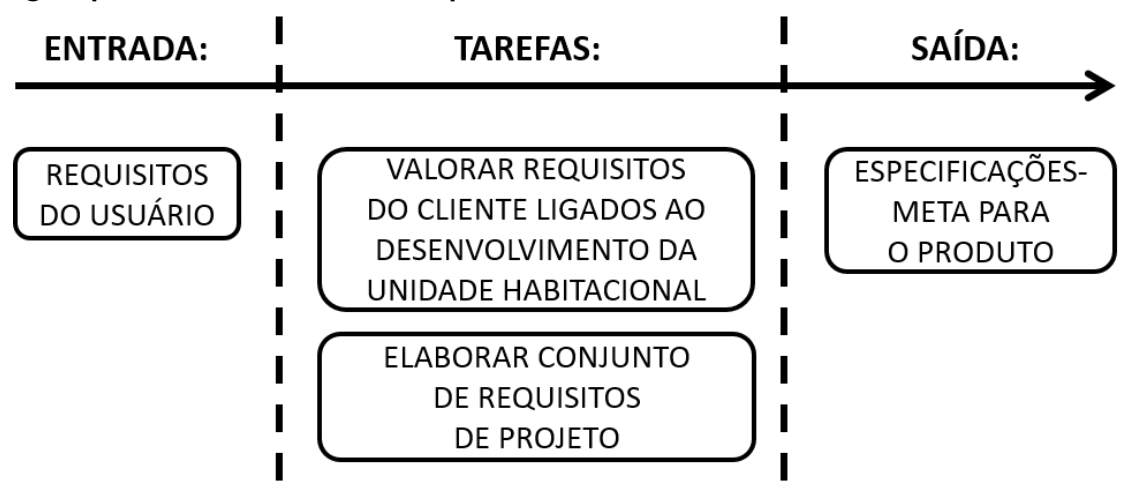


Para realização da terceira e última etapa de sistematização dos requisitos, caracterizada pela hierarquização dos requisitos de projeto e análise de restrições, fez-se uma adaptação da Casa da Qualidade do método QFD, de forma a identificar as relações existentes entre os requisitos do usuário e os requisitos de projeto. Foi elaborada também uma segunda matriz, a Matriz de Restrições, em que as interações entre os requisitos de projeto e as restrições legais, normativas e técnicas foram identificadas como favoráveis ou desfavoráveis à efetivação dos requisitos de projeto.

A Casa da Qualidade e a Matriz de Restrições proporcionam uma síntese dos dados a serem utilizados no processo de design e foram obtidas por meio dos passos a seguir.

\section{Casa da Qualidade}

Para a construção da Casa da Qualidade, primeiramente se lançaram nessa matriz os requisitos do usuário anteriormente organizados e valorados. Em seguida foi feita a descrição dos requisitos de projeto (potenciais atributos do produto), os quais devem afetar diretamente a percepção do usuário:
Fez-se o lançamento dos requisitos do usuário $(\mathrm{RU})$ e dos requisitos de projeto (RP) na Matriz da Qualidade, e definiram-se as relações existentes entre RU e RP, com a identificação das interações entre as características pretendidas para o produto e os requisitos do usuário, e determinação das intensidades de tais interações, representadas em progressão geométrica pelos números 9,3 e 1, que correspondem respectivamente a interações forte, moderada e fraca, conforme a área 1 , em destaque na Figura 7.

Com as interações definidas, os valores que determinam os níveis das interações $(9,3$ e 1) foram multiplicados pelos valores correspondentes à importância dos RU para o usuário (IGI\% índice geral de importância relativo). Exemplo na Figura 8.

Então essas operações foram somadas definindo-se o grau de importância absoluto de cada um dos requisitos de projeto. Exemplo na Figura 9.

Por fim, o grau de importância absoluto dos requisitos de projeto teve seus resultados ponderados em porcentagem, determinando um índice relativo aos respectivos requisitos de projeto. Exemplo na Figura 10.

Figura 7 - Exemplo de aplicação do QFD

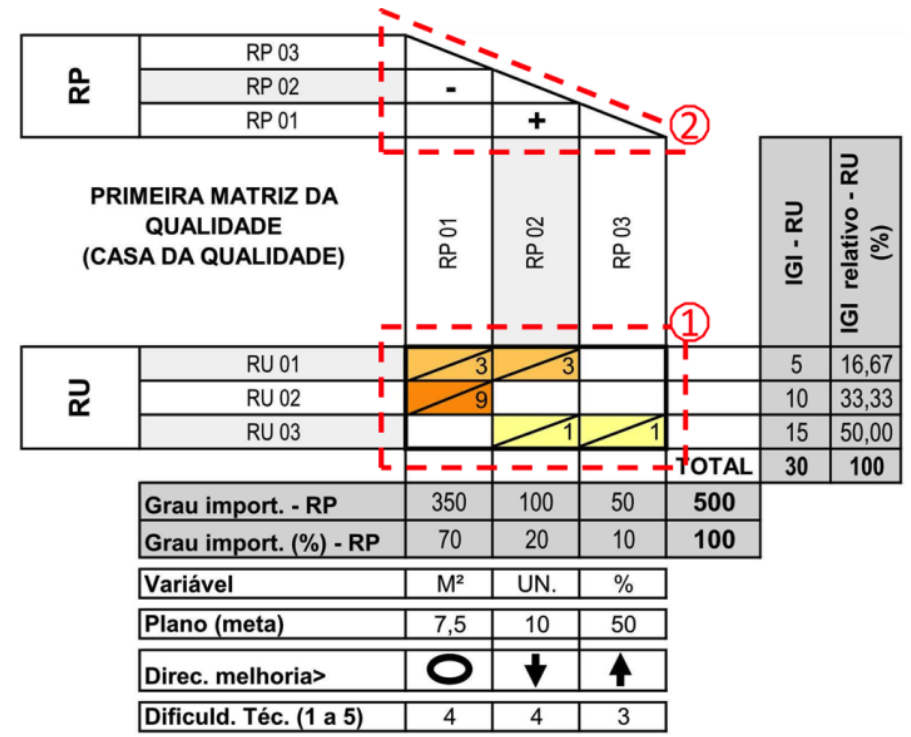

Figura 8 - Índice geral de importância relativo dos requisitos do usuário

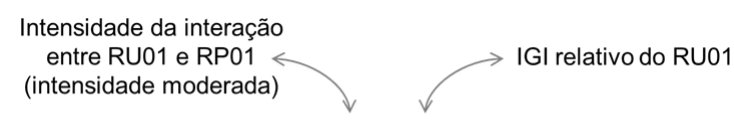

3. 16,67

280 Aragão, D. L. L. J. de; Hirota, E. H. 
Figura 9 - Grau de importância absoluto dos requisitos de projeto

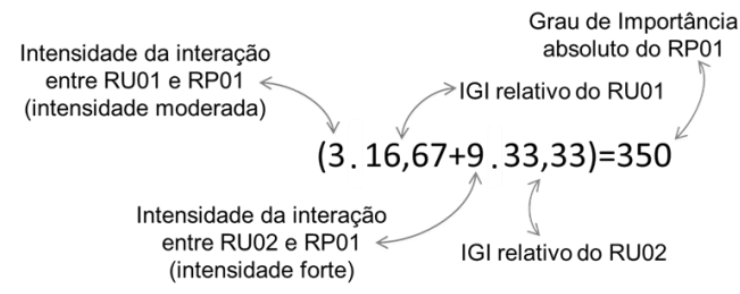

Figura 10 - Índice relativo aos respectivos requisistos de projeto

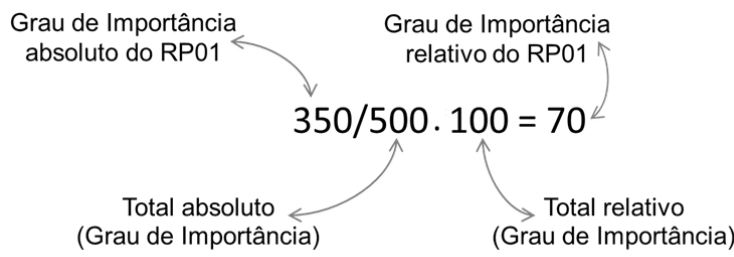

Para cada um dos requisitos de projeto foram definidas pela equipe metas mensuráveis (ex.: $\mathrm{RP} 01=7,5 \mathrm{~m}^{2}$ ) e o direcionamento apropriado de melhorias indicando se os esforços da equipe de desenvolvimento do projeto devem buscar acrescer $(\boldsymbol{\Delta})$, ou reduzir $(\boldsymbol{\nabla})$, ou se não importa a variação (O) das quantidades estabelecidas como metas. Além disso, foi definida a dificuldade técnica para cumprir tais metas estabelecidas (escala de 1 a 5). $\mathrm{O}$ nível 1 corresponde à meta que pode ser facilmente desenvolvida com a técnica construtiva adotada; o nível 2 indica que há possibilidade de desenvolvimento com a técnica construtiva adotada; o nível 3 , que pode ser facilmente desenvolvida com outra técnica construtiva; o nível 4, que é possível desenvolver com outra técnica construtiva; e o nível 5 indica que é difícil desenvolver mesmo com outra técnica construtiva.

Na parte superior da Matriz da Qualidade (telhado da matriz) são feitas as correlações entre os requisitos de projeto (RP), que variam entre correlações positivas, negativas e neutras, conforme área 2, em destaque na Figura 7. Essas correlações têm por objetivo auxiliar a equipe técnica na tomada de decisões sobre possíveis trade-offs entre os requisitos de projeto.

\section{Matriz de Restrições}

Para verificar a influência das restrições levantadas sobre os requisitos de projeto foi criada a Matriz de Restrições, na qual, a partir do lançamento das restrições e requisitos de projeto (RP), as interações existentes foram representadas pela importância "1" e "-1", que representam respectivamente as restrições positivas $\mathrm{e}$ as restrições negativas ao atendimento dos benefícios requisitados pelo usuário, conforme exemplifica a Figura 11.

Com a identificação das interações, as restrições positivas e negativas referentes a cada um dos requisitos de projeto foram contabilizadas, o que possibilitou a identificação da quantidade de restrições favoráveis e desfavoráveis à consideração de cada requisito de projeto durante o processo de design.

\section{Resultados e discussão Captura dos requisitos do usuário e
levantamento das restrições de
projeto}

Os dados coletados por meio do uso das cartas de preferências declaradas foram tratados estatisticamente, para possibilitar a identificação da ordem de importância dos tópicos abordados durante a aplicação das cartas. A Figura 12 apresenta, em ordem decrescente, os itens priorizados pelos usuários e, consequentemente, permite identificar possíveis oportunidades de intervenções no produto HIS.

A hierarquização dos requisitos do usuário, dada pelo IGI, pode indicar quais requisitos devem ser priorizados durante o processo de design, diante de recursos financeiros limitados, de forma que a tomada de decisões nesse processo ocorra em função das necessidades mais relevantes para o usuário. Desse modo, é possível observar na Figura 9 que, para o usuário, a segurança pessoal e do patrimônio deve ser priorizada, seguido de previsão de áreas verdes e medidas para redução de custos com água, energia e manutenção, e foi 
atribuída pouca importância relativa a itens como disposição dos cômodos, elementos decorativos e local para guardar carro.

Os esforços para a sintetização das restrições resultaram na redução de 173 para 102 restrições. A sintetização dessas informações representa maior facilidade para consultas e conferências segundo a equipe de PDP. Apesar da redução considerável da quantidade de itens, o número de restrições mostrou-se ainda elevado para a ilustração de sua totalidade diante da formatação adotada no presente artigo. Portanto, a Figura 13 apresenta uma amostra de um total de 102 itens coletados como restrições legais, normativas e disposições técnicas pertinentes ao desenvolvimento da UH. A lista completa dos itens supracitados encontra-se em Aragão (2014).

Figura 11 - Exemplo de aplicação da Matriz de Restrições

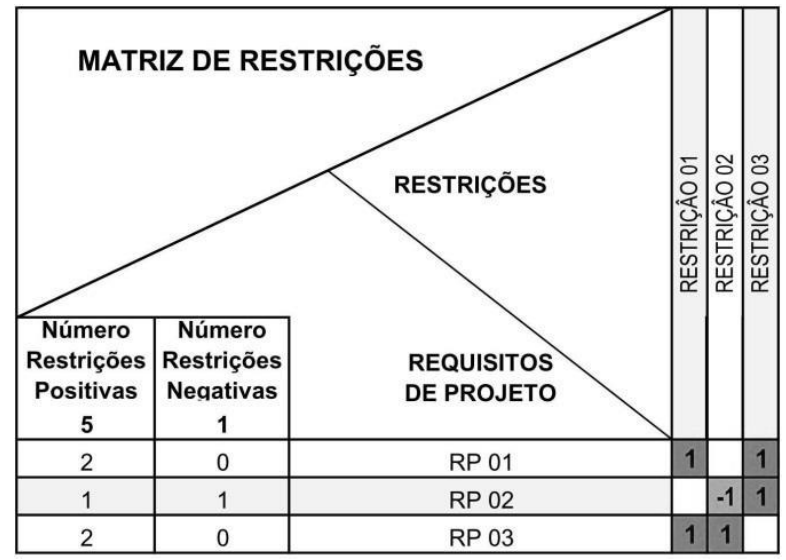

Figura 12 - Gráfico de valoração de requisitos do usuário (IGI)

Segurança (patrimônio e pessoal) Natureza (meio ambiente, áreas verdes, etc.) Gastar menos com as contas de água e luz Acústica da casa

Mais cômodos na casa

Gastar menos com prestações Qualidade (esquadrias, acabamentos, etc.) Privacidade (entre vizinhos e com a rua e passeio)

Tamanho dos cômodos Gastar menos com consertos, reparos e reformas Casa com área maior

Casas com aparências variadas

Ter oportunidade de negócios Conjunto menor (com menos casas)

Temperatura dentro da casa

Novos espaços (varanda, quintal, jardim, etc.) Áreas públicas (praças, ruas, áreas de convivência, etc.) A localização

Cômodos com formato mais adequado ao mobiliário

Iluminação dentro da casa

Tamanho e localização das portas e janelas Aparência das casas

Gastar menos com transportes Aparência do bairro

Local para guardar o carro Elementos decorativos Disposição dos cômodos

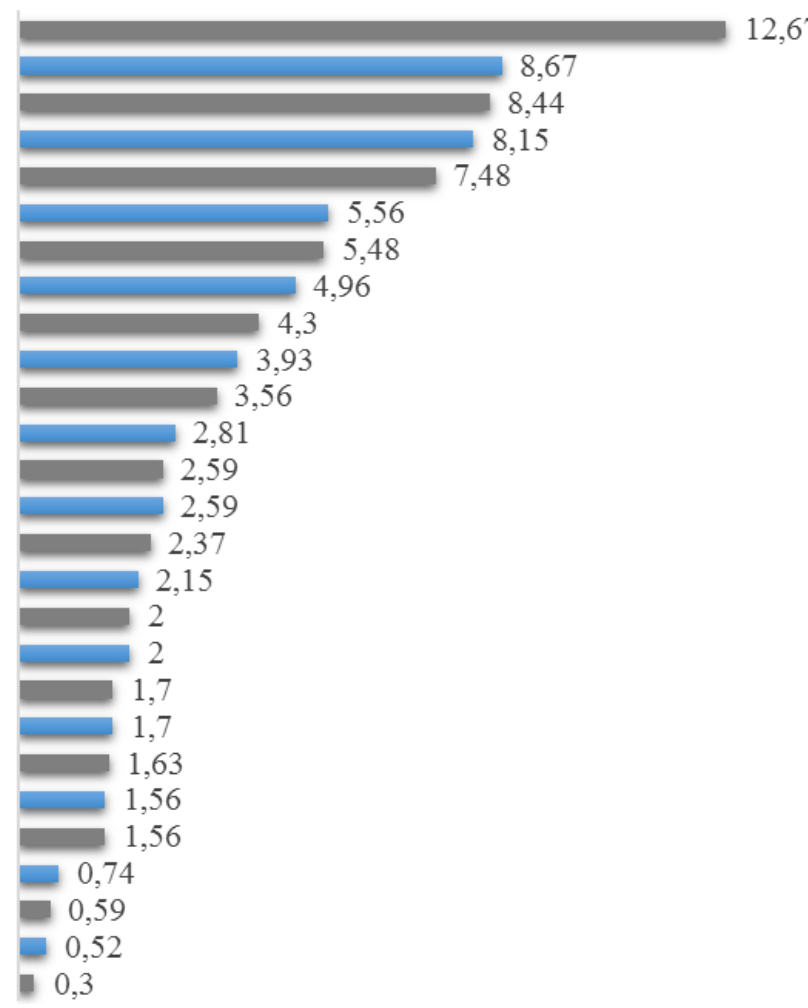

Fonte: modificado de Conceição, Imai e Urbano(2015). 
Figura 13 - Síntese das restrições legais e disposições técnicas pertinentes ao desenvolvimento da UH

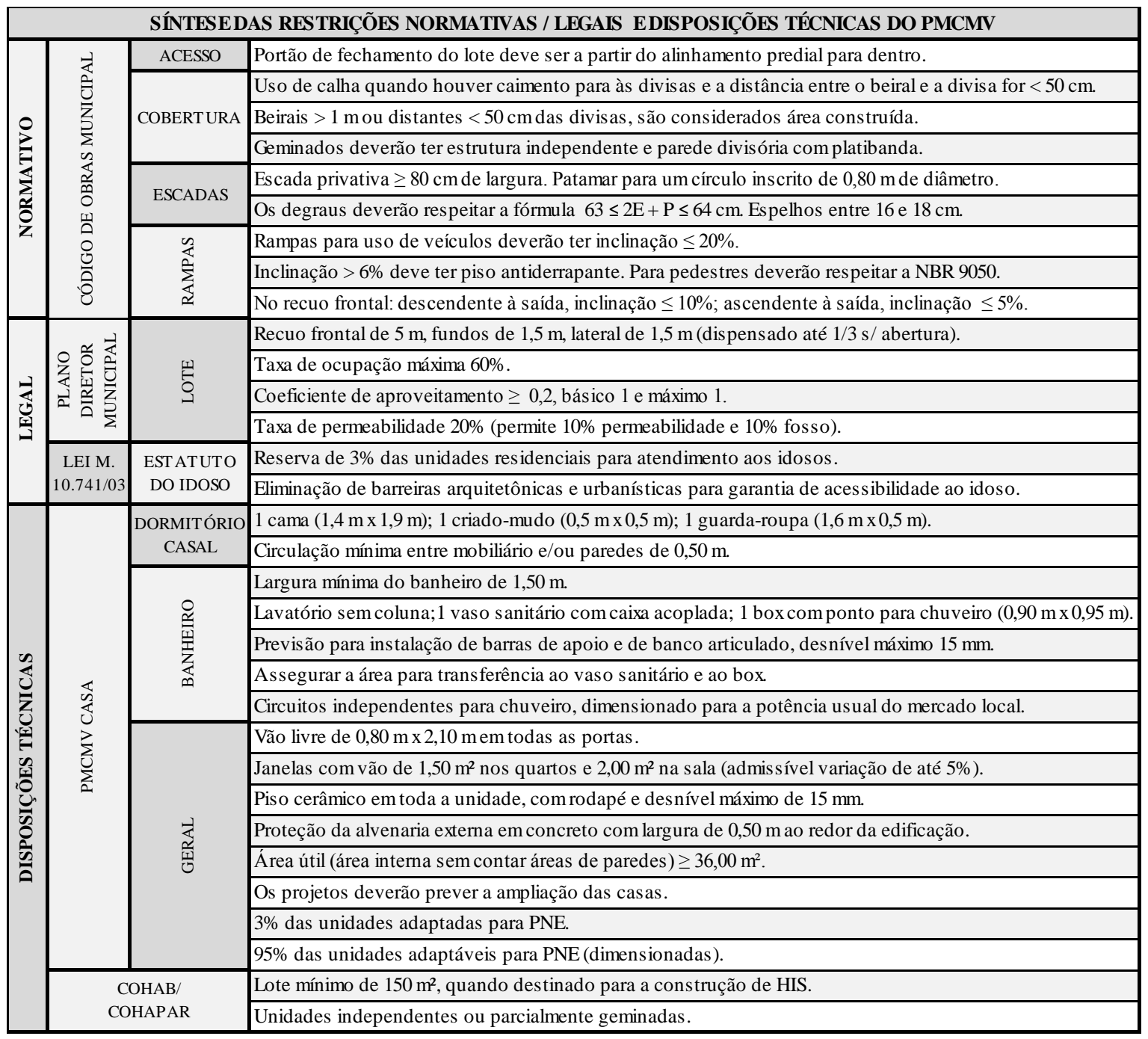

Os resultados obtidos nessa etapa indicaram a necessidade de desenvolvimento de uma forma eficaz de colocar à disposição dos envolvidos no processo de design de habitação de interesse social as informações sobre requisitos do usuário e restrições de projeto. Portanto, tais informações deveriam ser dispostas em um formato que propiciasse a compreensão da equipe de desenvolvimento do produto e favorecesse a tomada de decisão no processo de design.

\section{Sistematização dos requisitos do usuário e das restrições de projeto}

Para que os requisitos do usuário fossem priorizados durante o processo de design, de forma que a tomada de decisões nesse processo ocorresse em função das necessidades requeridas pelo usuário, mostrou-se fundamental a hierarquização dos requisitos do usuário relacionados à unidade habitacional, para, assim, poder gerenciar possíveis trade-offs durante o processo de design do produto.

A exemplo do que se fez com o conjunto de restrições e especificações técnicas, optou-se por ocultar dessa etapa as informações não relacionadas ao desenvolvimento da unidade habitacional, as quais se referem ao meio urbano, loteamento, localização do empreendimento e infraestrutura. Dessa forma, dos 27 requisitos do usuário avaliados na APO 5 foram avaliados como secundários, ou por não terem relação direta com a unidade habitacional, como é o caso dos itens conjuntos menores, localização e áreas públicas, ou por terem sido inclusos na aplicação da APO por motivações específicas de outras pesquisas, como os itens gastar menos com prestações e gastar menos com transportes.

A Figura 14 apresenta os 22 itens que representam os requisitos do usuário relativos ao desenvolvimento da unidade habitacional. O IGI 
desses itens foi ponderado de forma a apresentarem valores relativos representados por variáveis em percentagens.

A etapa de elaboração do conjunto de requisitos de projeto mostrou-se uma tarefa bastante complexa, sobretudo por seu caráter abstrato, pois não foi possível identificar na literatura diretrizes bem definidas para a elaboração de tais requisitos de projeto para o desenvolvimento de produtos da construção civil.

Nessa etapa alguns cuidados foram tomados para a reformulação do conjunto de requisitos de projeto.
Somente requisitos de projeto mensuráveis foram definidos para que houvesse a possibilidade de definir metas para eles, ou seja, se o requisito definido puder ser mensurado, poderá ser definida uma meta a ser cumprida durante a tomada de decisões no processo de projeto. Atentou-se também para o número de requisitos de projeto definidos, para que essa lista fosse a mais coesa possível. A Figura 15 apresenta a lista de requisitos de projeto definida nesta etapa, juntamente com as especificações-metas.

Figura 14 - Requisitos do usuário pertinentes e com índices de importância ponderados

\begin{tabular}{|c|l|c|c|}
\hline $\mathbf{N}^{\circ}$ & \multicolumn{1}{|c|}{$\begin{array}{c}\text { REQUISITOS Do USUÁRIO } \\
\text { (Índice Geral de Importância) }\end{array}$} & $\begin{array}{c}\text { IGI } \\
\text { absoluto }\end{array}$ & $\begin{array}{c}\text { IGI relativo } \\
(\%)\end{array}$ \\
\hline 1 & Segurança (patrimônio e pessoas) & 12,67 & $\mathbf{1 4 , 6 8}$ \\
\hline 2 & Natureza (meio ambiente, áreas verdes, ar puro, reciclagem) & 8,67 & $\mathbf{1 0 , 0 5}$ \\
\hline 3 & Gastar menos com as contas de água, luz, outros & 8,44 & $\mathbf{9 , 7 8}$ \\
\hline 4 & Acústica da casa (barulhos: de fora, vizinhos, entre cômodos) & 8,15 & $\mathbf{9 , 4 4}$ \\
\hline 5 & Mais cômodos na casa & 7,48 & $\mathbf{8 , 6 7}$ \\
\hline 6 & Qualidade (esquadrias, acabamentos, hidráulica, elétrica) & 5,48 & $\mathbf{6 , 3 5}$ \\
\hline 7 & Privacidade (entre vizinhos, com a rua e passeio) & 4,96 & $\mathbf{5 , 7 5}$ \\
\hline 8 & Tamanho dos cômodos & 4,3 & $\mathbf{4 , 9 8}$ \\
\hline 9 & Gastar menos com consertos, reparos e reformas & 3,93 & $\mathbf{4 , 5 5}$ \\
\hline 10 & Casa com área maior & 3,56 & $\mathbf{4 , 1 3}$ \\
\hline 11 & Casas com aparência variada & 2,81 & $\mathbf{3 , 2 6}$ \\
\hline 12 & Ter oportunidade de negócios & 2,59 & $\mathbf{3 , 0 0}$ \\
\hline 13 & Temperatura dentro da casa & 2,37 & $\mathbf{2 , 7 5}$ \\
\hline 14 & Novos espaços (varanda, quintal, jardim) & 2,15 & $\mathbf{2 , 4 9}$ \\
\hline 15 & Cômodos com formato mais adequado ao mobiliário & 1,7 & $\mathbf{1 , 9 7}$ \\
\hline 16 & lluminação dentro da casa & 1,7 & $\mathbf{1 , 9 7}$ \\
\hline 17 & Tamanho e localização das portas e janelas & 1,63 & $\mathbf{1 , 8 9}$ \\
\hline 18 & Aparência das casas & 1,56 & $\mathbf{1 , 8 1}$ \\
\hline 19 & Aparência do bairro (fachadas, limpeza, cores, telhados) & 0,74 & $\mathbf{0 , 8 6}$ \\
\hline 20 & Local para guardar o carro & 0,59 & $\mathbf{0 , 6 8}$ \\
\hline 21 & Elementos decorativos & 0,52 & $\mathbf{0 , 6 0}$ \\
\hline 22 & Disposição dos cômodos (localização de cada cômodo) & 0,3 & $\mathbf{0 , 3 5}$ \\
\hline- & Gastar menos com prestações, financiamento e alugueł & 5,56 & - \\
\hline- & Conjuntos menores (com menos casas) & 2,59 & - \\
\hline- & Areas públicas (praças, ruas, áreas de convivencia) & 2,00 & - \\
\hline- & A Localização & 2,00 & - \\
\hline- & Gastar menos com transportes & 1,56 & - \\
\hline & & 100 & $\mathbf{1 0 0}$ \\
\hline
\end{tabular}


Figura 15 - Conjunto de requisitos de projeto

\begin{tabular}{|c|c|c|}
\hline REQUISTTOS DO USUÁRIO & REQUISITOS DE PROJETO & $\begin{array}{c}\text { ESPECIFICAÇA } \\
\text { O } \\
\text { META } \\
\end{array}$ \\
\hline Segurança & Fechamento da UH com muro & $23,5 \mathrm{~m}$ \\
\hline \multirow[t]{2}{*}{ Privacidade } & Bloqueio visual nas aberturas laterais (entre unidades vizinhas) & $70 \%$ \\
\hline & UH independente (não geminada) & $100 \%$ \\
\hline Aparência do bairro (fachadas, limpeza, cores...) & \multirow{2}{*}{ Variedade de fachada } & \multirow{2}{*}{4 un. } \\
\hline Elementos decorativos & & \\
\hline Aparência das casas & \multirow{2}{*}{ Frente mínima do lote } & \multirow{2}{*}{$7 \mathrm{~m}$} \\
\hline Natureza (áreas verdes, ar puro, reciclagem...) & & \\
\hline Gastar menos com contas de água, luz... & Capacidade e eficiência do Sistema de aquecimento solar & $0,2 \mathrm{~m}^{3}$ \\
\hline Ter oportunidade de negócios & Cômodo suplementar (área para comércio/serviço) & $8 m^{2}$ \\
\hline \multirow[t]{2}{*}{ Mais cômodos na casa } & Cômodo suplementar ( $3^{\circ}$ dormitório) & $7 \mathrm{~m}^{2}$ \\
\hline & Área de serviço funcional coberta & $3 \mathrm{~m}^{2}$ \\
\hline \multirow[t]{2}{*}{ Casa com área maior } & Minimizar área de corredores dentro da unidade & $1,5 \mathrm{~m}^{2}$ \\
\hline & Projeto de ampliação da UH & $15 \mathrm{~m}^{2}$ \\
\hline Gastar menos com consertos e reformas & Abertura para ampliação (friso para recorte na parede) & 1 un. \\
\hline Local para guardar o carro & Construção complementar (garagem) & $10 \mathrm{~m}^{2}$ \\
\hline
\end{tabular}

É importante esclarecer que esta e as demais etapas de sistematização de requisito foram desenvolvidas com a integração de profissionais das áreas de projeto, construção e promoção de habitações de interesse social, por meio de trabalho colaborativo, o qual influenciou positivamente os membros da equipe e permitiu o intercâmbio e compartilhamento de conhecimento entre os agentes do processo, uma compreensão comum sobre as decisões tomadas e suas implicações. Isso representou, entre outras coisas, o comprometimento dos membros da equipe em relação à implementação das metas assumidas.

Posteriormente a essas ações foram identificadas as interações entre os requisitos do usuário e os requisitos de projeto lançados na matriz. Portanto, foram definidas as interações entre as características pretendidas para o produto e os requisitos do usuário, bem como foi determinado o grau de interação, conforme Kamara, Anumba e Evbuomwan (1999), indicado pelos números 9, 3 e 1 .
Com as interações definidas, os valores que definem o grau das interações foram multiplicados pelos valores correspondentes à importância dos requisitos do usuário, estabelecidos anteriormente, e a soma destas multiplicações foram ponderadas em porcentagem que determina índices aos respectivos requisitos de projeto.

Assim, os produtos dessa etapa são representados pelo dispositivo visual (Matriz da Qualidade). A Figura 16 esboça a estrutura da Matriz da Qualidade, apresentando sua divisão em algumas seções básicas. Apresenta também uma síntese de um total de 510 interações e correlações analisadas $^{3}$ na matriz, elaborada a partir de exemplos e recomendações da literatura, como uma adaptação para o setor da construção civil.

A construção dessa matriz proporciona a identificação da relação e da intensidade existente entre os requisitos do usuário e os requisitos de projeto. Esse conhecimento auxilia o processo de

${ }^{3} \mathrm{O}$ quadro com a totalidade das interações e correlações analisadas na matriz, bem como outros detalhes adicionais, pode ser disponibilizado mediante contato com os autores. 
tomada de decisão à medida que indica como cada requisito do usuário intervém nos requisitos de projeto. Com isso, durante o desenvolvimento do produto, pode-se ter maior controle na tomada de decisão, pois a escolha por um ou por outro requisito, diante das limitações orçamentárias, pode ser realizada de maneira mais racional. Porém, para que essas informações sejam confiáveis, é necessário que sejam também estabelecidas pelos membros da equipe envolvida no desenvolvimento do produto. Embora o processo possa ser mais demorado, havendo a análise das relações por todos os membros da equipe, ele se torna mais confiável.

Com base no exposto, a Figura 17 apresenta uma síntese das mais de 1.650 interações analisadas na Matriz de Restrições elaborada. A lista completa dos itens supracitados encontra-se em Aragão (2014).

Figura 16 - Síntese das interações da Matriz da Qualidade

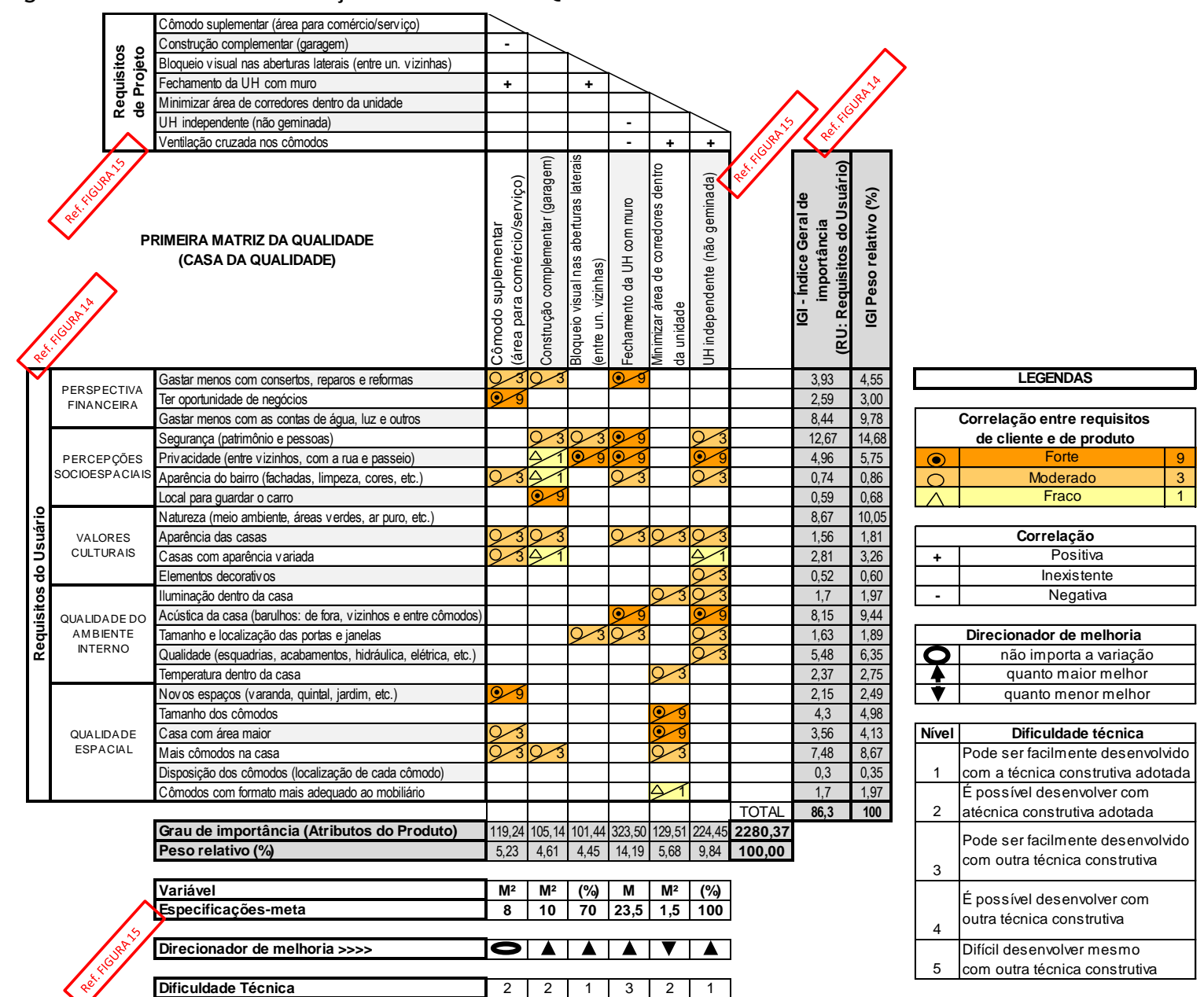

286 Aragão, D. L. L. J. de; Hirota, E. H. 
Figura 17 - Matriz de Restrições

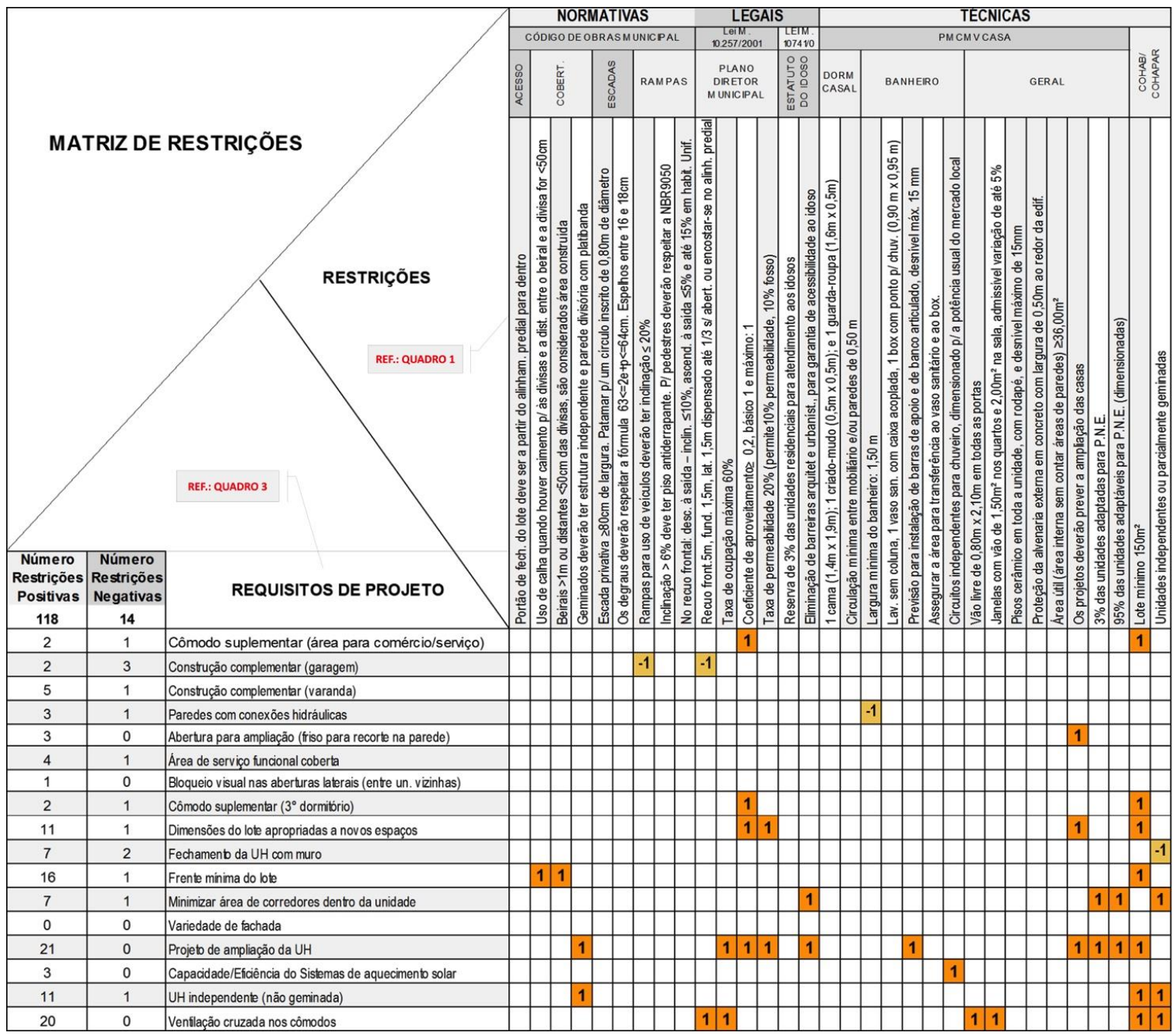

Esse conjunto de matrizes tem como objetivo principal possibilitar que as decisões tomadas durante o processo de concepção do produto sejam coerentes com as necessidades do usuário, possibilitando que equipe técnica trabalhe em conformidade com as solicitações dele. Uma vez que as interações foram identificadas com o auxílio das matrizes aplicadas, foi possível hierarquizar o conjunto de requisitos de projeto, atribuindo a estes um grau de importância relativo. As matrizes também possibilitaram consulta às restrições relacionadas aos requisitos de projeto, as inter-relações entre os mesmos, a dificuldade técnica em cumprir cada um dos requisitos de projeto, e o direcionamento apropriado de melhorias para produto.
A Figura 18 sintetiza os resultados obtidos no processamento dos requisitos do usuário nas matrizes adaptadas do QFD.

A Figura 18 teve como principal objetivo auxiliar a tomada de decisões durante o processo criativo, possibilitando maior eficiência na ponderação de trade-offs, entre as solicitações do usuário e a limitação de recursos financeiros. A indicação do grau de importância dos requisitos de projeto possibilita que as necessidades mais emergentes do usuário sejam priorizadas durante o processo de design. Espera-se que tais informações propiciem que o processo de design tenha sempre como referência as necessidades do usuário, de forma a possibilitar que recursos financeiros sejam aplicados para a inserção de itens que agreguem mais valor para o usuário. 
Figura 18 - Hierarquia dos Requisitos de Projeto

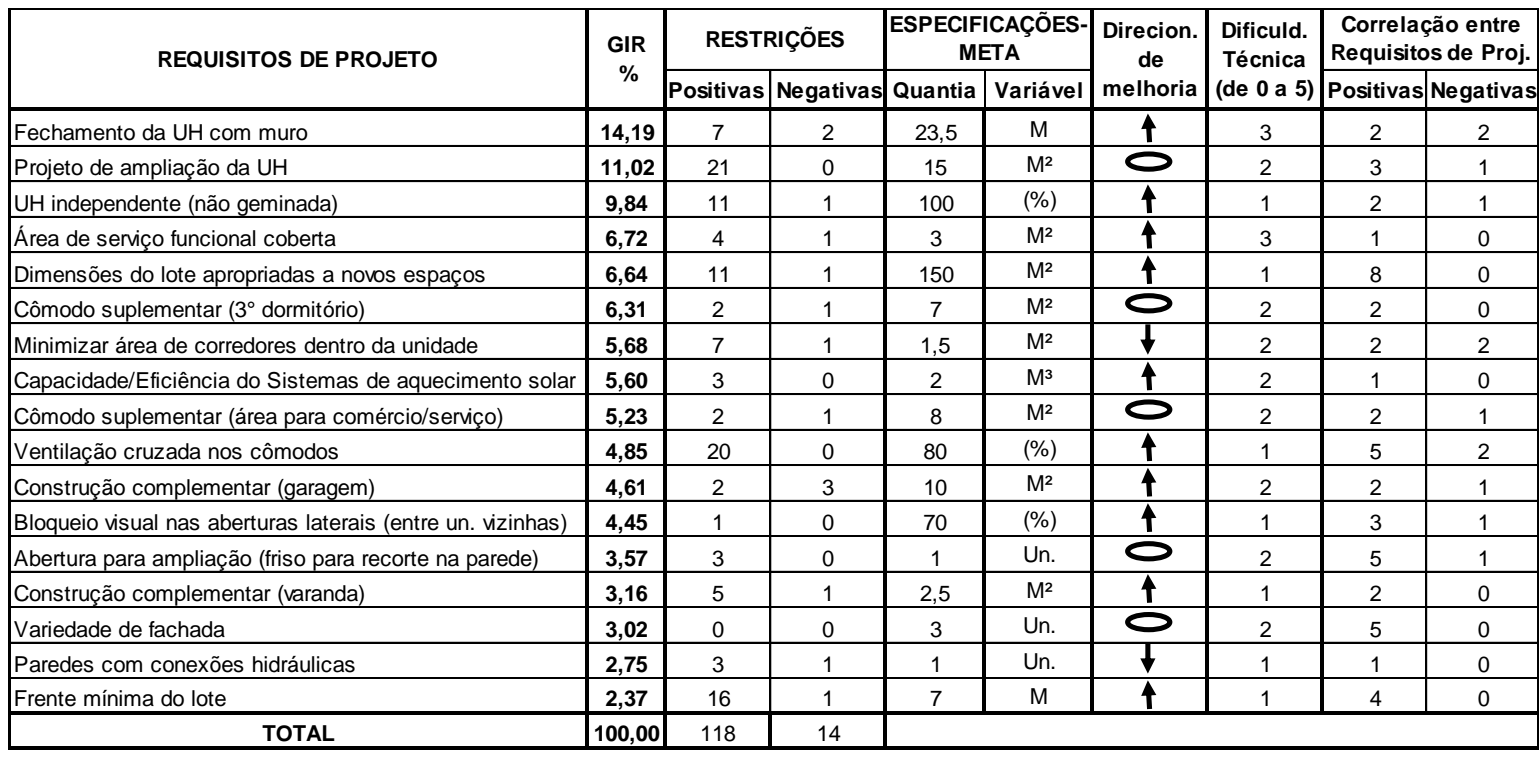

\begin{tabular}{|c|l|}
\hline Nível & \multicolumn{1}{|c|}{ Dificuldade técnica } \\
\hline 1 & Facilmente desenvolvido com a técnica construt. adotada \\
\hline 2 & É possível desenvolver com atécnica construtiva adotada \\
\hline 3 & Pode ser facilmente desenvolvido com outra técnica construtiva \\
\hline 4 & É possível desenvolver com outra técnica construtiva \\
\hline 5 & Difícil desenvolver mesmo com outra técnica construtiva \\
\hline
\end{tabular}

\begin{tabular}{|c|c|}
\hline \multicolumn{2}{|c|}{ Direcionador de melhoria } \\
\hline & Não importa a variação \\
\hline $\mathbf{1}$ & Quanto maior melhor \\
\hline$\downarrow$ & Quanto menor melhor \\
\hline
\end{tabular}

GIR - Grau de importância relativo

Restrições Posit. - Vavoráveis aos Requisitos de Projeto

Restrições Negativas - Desfavoráveis aos Requisitos de Projeto

\section{Conclusões}

Este artigo apresentou, como contribuição científica, procedimentos para estruturar e organizar os requisitos do usuário para o desenvolvimento de projetos habitacionais de interesse social, desenvolvidos, a partir da sistematização de revisão de literatura sobre o assunto, em um caso real de processo de projeto, com a pretensão de auxiliar o processo de tomada de decisões e, consequentemente, o incremento de valor por meio de soluções projetuais de maior qualidade e eficiência.

Os resultados obtidos permitem concluir que com o uso da Casa da Qualidade do QFD é possível hierarquizar e objetivar requisitos de clientes/usuários, apresentados de forma sintética na Figura 18, principalmente ao se considerar que esse quadro atendeu a uma equipe de projetistas trabalhando em um caso real de desenvolvimento de projeto de HIS pelo período de aproximadamente 8 meses.

Entre os benefícios almejados com o uso dos procedimentos propostos destacam-se a definição das prioridades por meio da realização de fóruns de discussões com a participação dos profissionais envolvidos no processo de desenvolvimento do produto e colaboradores; e síntese hierárquica dos requisitos de projetos, com o estabelecimento de metas como contraponto às limitações de recursos financeiros.

A aplicação da Casa da Qualidade do QFD permitiu a ordenação, transformação e hierarquização dos requisitos do usuário, bem como a disposição deles em formato que ampliou a compreensão por parte da equipe envolvida no desenvolvimento do produto habitacional.

Contudo, compete observar que existem lacunas a serem preenchidas, apontadas aqui como sugestões para pesquisas futuras, a saber.

(a) Em que medida a experiência dos membros da equipe de desenvolvimento do produto deste estudo afetou a exequibilidade dos procedimentos adotados? e

(b) Como incluir as restrições orçamentárias no desenvolvimento do projeto de HIS?

\section{Referências}

AKAO, Y. QFD: past, present, and future. In: INTERNATIONAL SYMPOSIUM ON QFD, 3., Linköping, 1997. Proceedings... Linköping, 1997. 
ARAGÃO, D. L. L. J. Subsídios Para Aplicação do Custeio-Meta na Etapa de Concepção de Unidades Habitacionais de Interesse Social no Âmbito do PMCMV. Londrina, 2014. 118 f. Dissertação (Mestrado em Engenharia de Edificações e Saneamento) - Escola de Engenharia, Universidade Estadual de Londrina, Londrina, 2014.

\section{ASSOCIAÇÃO BRASILEIRA DE NORMAS} TÉCNICAS. NBR-ISO 12006-2: construção de edificação: organização de informação da construção: parte 2: estrutura para classificação de informação. Rio de Janeiro, 2010.

\section{ASSOCIAÇÃO BRASILEIRA DE NORMAS}

TÉCNICAS. NBR 15.575-1: edificações habitacionais: desempenho: parte 1: requisitos gerais. Rio de Janeiro, 2013.

\section{ASSOCIAÇÃO BRASILEIRA DE NORMAS} TÉCNICAS. NBR 15.575-2: edificações habitacionais: desempenho: parte 2: requisitos para os sistemas estruturais. Rio de Janeiro, 2013.

\section{ASSOCIAÇÃO BRASILEIRA DE NORMAS} TÉCNICAS. NBR 15.575-3: edificações habitacionais: desempenho: parte 3: requisitos para os sistemas de pisos. Rio de Janeiro, 2013.

\section{ASSOCIAÇÃO BRASILEIRA DE NORMAS} TÉCNICAS. NBR 15.575-4: edificações habitacionais: desempenho: parte 4: requisitos para os sistemas de vedações verticais internas e externas. Rio de Janeiro, 2013.

\section{ASSOCIAÇÃO BRASILEIRA DE NORMAS TÉCNICAS. NBR 15.575-5: edificações} habitacionais: desempenho: parte 5: requisitos para os sistemas de coberturas. Rio de Janeiro, 2013.

\section{ASSOCIAÇÃO BRASILEIRA DE NORMAS} TÉCNICAS. NBR 15.575-6: edificações habitacionais: desempenho: parte 5: requisitos para os sistemas hidrossanitários. Rio de Janeiro, 2013.

AUSTIN, S. A. et al. Integrated collaborative Design. Journal of Engineering, Design and Technology, v. 5, n. 1, p. 7-22, 2007.

BALDAUF, J. P.; FORMOSO, C. T.; MIRON, L. I. G. Modelagem de Requisitos de Clientes de Empreendimentos Habitacionais de Interesse Social Com o Uso de BIM. Ambiente Construído, Porto Alegre, v. 13, n. 3, p. 177-195, jul./set. 2013.

BARRETT, P. S.; HUDSON, J.; STANLEY, C. Good Practice in Briefing: the limits of rationality. Automation in Construction, v. 8, n. 6, p. 633642, 1999.
BECKER, A. C. et al. Metodologia Para Elaboração de Projetos Com o Uso da EV e QFD: aplicação ao empreendimento Cetec-UPF. Estudos Tecnológicos em Engenharia, v. 4, n. 3, p. 231250, 2008.

BRANDÃO, D. Q. Disposições Técnicas e Diretrizes Para Projeto de Habitações Sociais Evolutivas. Ambiente Construído, Porto Alegre, v. 11, n. 2, p. 73-96, abr./jun. 2011.

BRASIL. Lei $\mathrm{n}^{\circ} 10.741$, de $1^{\circ}$ de outubro de 2003, Estatuto do Idoso, que dispõe sobre o Estatuto do Idoso e dá outras providências. Diário Oficial da República, 02 de outubro de 2003.

\section{CAIXA ECONÔMICA FEDERAL. Cartilha Completa sobre o Programa Minha Casa Minha Vida. Brasília, 2012.}

CONCEIÇÃO, P. A.; IMAI, C.; URBANO, M. R. Captura e Hierarquização de Requisitos do clieNte de Habitação de Interesse Social a Partir da Avaliação Pós-Ocupação e da Técnica de Preferência Declarada. Gestão \& Tecnologia de Projetos, v.10, n. 1, p. 79-98, 2015.

COOPER, R. G. Product Leadership: creating and launching superior new products. [S.1.]: Da Capo Press, 1999.

COOPER, R.; SLAGMULDER, R. Target Costing and Value engiNeering. Portland: Productivity Press, 1997.

CUNHA, G. D. A Evolução dos Modos de Gestão do Desenvolvimento de Produtos. Produto \& Produção, v. 9, n. 2, p. 71-90, 2008.

DIKMEN, I.; TALAT BIRGONUL, M.; KIZILTAS, S. Strategic Use of Quality Function Deployment (QFD) in the Construction Industry. Building and Environment, v. 40, n. 2, p. 245255, 2005.

HAN, B. S. et al. A Conceptual QFD Planning Model. International Journal of Quality \& Reliability Management, v. 18, n. 8, p. 796-812, 2001.

HAUSER, J. R.; CLAUSING, D. The House of Quality. Harvard Business Review, v. 66, n. 3, p. 63-73, May/Jun. 1988.

INSTITUTO NACIONAL DE METROLOGIA, NORMALIZAÇÃO E QUALIDADE INDUSTRIAL. Avaliação da Conformidade: diretoria da qualidade. 5. ed. Rio de Janeiro: Inmetro, 2007.

KAMARA, J. M.; ANUMBA, C. J.; EVBUOMWAN, N. F. O. Client Requirements Processing in Construction: a new approach using QFD. Journal of Architectural Engineering, v. 5, n. 1, p. 8-15, Mar. 1999. 
KANASHIRO, M.; GUADANHIM, S. J.; DEMORI, A. Organização Espacial de Novos Projetos de Habitação Coletiva. In: SEMINÁRIO INTERNACIONAL NUTAU - BRICS E HABITAÇÃO COLETIVA SUSTENTÁVEL, 9., São Paulo, 2012. Anais... São Paulo: USP, 2012.

KOSKELA, L. An Exploration Towards a Production Theory and Its Application to Construction. Helsinki, 2000. 296 f. Thesis (Ph.D.) - Technical Research Centre of Finland, Helsinki, 2000.

KOWALTOWSKI, D. C. C. K.; GRANJA, A. D. The Concept of Desired Value as a Stimulus for Change in Social Housing in Brazil. Habitat International, v. 35, n. 3, p. 435-446, 2011.

LIMA, L. P.; FORMOSO, C. T.; ECHEVESTE, M. E. S. Proposta de Um Protocolo Para o Processamento de Requisitos do Cliente em Empreendimentos Habitacionais de Interesse Social. Ambiente Construído, Porto Alegre, v. 11, n. 2, p. 21-37, abr./jun. 2011.

LOGSDON, L. O Programa Minha Casa, Minha Vida em Cuiabá-MT: uma análise da qualidade dos projetos destinados às famílias de baixa renda. Florianópolis, 2012. Dissertação (Mestrado em Engenharia Civil) - Programa de Pós-Graduação em Arquitetura e Urbanismo, Universidade Federal de Santa Catarina, Florianópolis, 2012.

LONDRINA. Câmara Municipal. Lei Municipal $\mathbf{n}^{\mathbf{0}}$ 11.381, de 21 de novembro de 2011, Código de Obras e Edificações do Município de Londrina. Londrina, 2011

LONDRINA. Câmara Municipal. Lei Municipal $\mathbf{n}^{\mathbf{0}}$. 7.482, Plano Diretor Participativo do Município de Londrina - PDPML, de 20 de julho de 1998.

\section{MINISTÉRIO DAS CIDADES. Cidades Para}

Todos. Brasília: Ministério das Cidades, 2004.

MIRON, L. I. G. Gerenciamento dos Requisitos dos Clientes de Empreendimentos

Habitacionais de Interesse Social: proposta para o Programa Integrado Entrada da Cidade em Porto Alegre/RS. Porto Alegre, 2008. 350 f. Tese (Doutorado em Engenharia Civil) - Escola de Engenharia, Universidade Federal do Rio Grande do Sul, Porto Alegre, 2008.

OLIVEIRA, R. de. Desempenhos Críticos Para Sustentabilidade Habitacional. In: CONGRESSO BRASILEIRO E II IBEROAMERICANO HABITAÇÃO SOCIAL: CIÊNCIA E TECNOLOGIA, 2., Florianópolis, 2006. Anais... Florianópolis, 2006.
OZORIO, K. B. K. Recomendações Para o Gerenciamento de Equipes Multidisciplinares no Desenvolvimento de Projeto de Edificações, Com Foco na Colaboração. Londrina, 2012. 109 f. Dissertação (Mestrado em Engenharia de Edificações e Saneamento) - Escola de Engenharia, Universidade Estadual de Londrina, Londrina, 2012.

PALERMO, C. et al. Habitação Social: uma visão projetual. In: COLÓQUIO DE PESQUISAS EM HABITAÇÃO, 4., Belo Horizonte, 2007. Anais... Belo Horizonte, 2007.

PRASAD, B. Review of QFD and Related Deployment Techniques. Journal of

Manufacturing Systems, v. 17, n. 3, p. 221-234, 1998.

QUEIROZ, F.; TRAMONTANO, M.

Apartamentos Paulistanos: um olhar sobre a produção privada recente. Ambiente Construído, Porto Aelgre, v. 9, n. 2, p. 139-150, abr./jun. 2009.

ROBIN, V.; ROSE, B.; GIRARD, P. Modelling Collaborative Knowledge to Suport Engineering Design Project Manager. Journal Computers in Industry, v. 58, n. 2, p. 188-198, Feb. 2007.

SALGADO, E. G. et al. Identificação das Ferramentas da Filosofia Lean Para Aplicação no Processo de Desenvolvimento de Produtos. In: SIMPÓSIO DE ENGENHARIA DE PRODUÇÃO, 8., São Paulo, 2006. Anais... São Paulo, 2006.

SALVATIERRA-GARRIDO, J; PASQUIRE, C.; MIRON, L. Exploring Value Concept Through the IGLC Community: nineteen years of experience. In: ANNUAL CONFERENCE OF THE INTERNATIONAL GROUP FOR LEAN CONSTRUCTION, 20., San Diego, 2012. Proceedings... San Diego, 2012.

SAMPAIO, J. C. S. et al. Modelo de Retroalimentação do Processo de Projeto a Partir de Informações Sobre Satisfação de Clientes. Ambiente Construído, Porto Alegre, v. 11, n. 4, p. 129-149, out./dez. 2011.

SOMMERVILLE, J.; CRAIG, N. The Application of Quality Function Deployment in the IT/Construction Industries. In: RICS FOUNDATION CONSTRUCTION AND BUILDING RESEARCH CONFERENCE, 2002. Proceedings... Nottingham Trent University, 2002.

THIA, C. W. et al. An Exploratory Study of the Use of Quality Tools and Techniques in Product Development. The TQM Magazine, v. 17, n. 5, p. 406-424, 2005. 
THIEME, J. Perspective: the world's top innovation management scholars and their social capital. Journal of Product Innovation Management, v. 24, n. 3, p. 214-229, 2007.

YANG, Y. Q. et al. A Fuzzy Quality Function Deployment System for Buildable Design Decision-Makings. Automation in Construction, v. 12, n. 4, p. 381-393, 2003.

\section{Agradecimentos}

Os autores agradecem à Capes, pelo apoio a esta pesquisa, e à Cohab-LD e à empresa Terra Nova, pela colaboração.

Danilton Luis Lima Jesus de Aragão

Departamento de Arquitetura e Urbanismo | Centro Universitário Filadélfia | Av. Juscelino Kubitschek, 1870, Centro | Londrina - PR Brasil | CEP 86.020-001 | Tel.: (43) 3375-7567 | E-mail: danilton.aragao@unifil.br

\section{Ercília Hitomi Hirota}

Departamento de Construção Civil, Centro de Tecnologia e Urbanismo | Universidade Estadual de Londrina | Rodovia Celso Garcia Cid, PR 445, km 380, Jardim Sabará I | Caixa Postal 6001 | Londrina - PR - Brasil | CEP 86051-970 | Tel.: (43) 3371-4460 | E-mail: ercilia@uel.br

\section{Revista Ambiente Construído}

Associação Nacional de Tecnologia do Ambiente Construído

Av. Osvaldo Aranha, $99-3^{\circ}$ andar, Centro

Porto Alegre - RS - Brasil

CEP 90035-190

Telefone: +55 (51) 3308-4084

Fax: +55 (51) 3308-4054

www.seer.ufrgs.br/ambienteconstruido

E-mail: ambienteconstruido@ufrgs.br 